\title{
Basic Study of Blind Football Play-by-Play System for Visually Impaired Spectators Using Quasi-Zenith Satellites System
}

\author{
Makoto Kobayashi $^{1(\sqrt{(})}$, Yoshiki Fukunaga ${ }^{1}$, and Shigenobu Shimada ${ }^{2}$ \\ ${ }^{1}$ Department of Computer Science, Tsukuba University of Technology, Tsukuba, Japan \\ \{koba, fukunaga\} @cs.k.tsukuba-tech.ac.jp \\ ${ }^{2}$ R\&D Department, Tokyo Metropolitan Industrial Technology Research Institute, Tokyo, Japan \\ shimada.shigenobuliri-tokyo.jp
}

\begin{abstract}
A project to develop a blind football play-by-play system was started. The target of the system is visually impaired spectator. To conduct a basic study, we made an experimental system that detects a position of a player using a QuasiZenith Satellites System (QZSS) and shows the position via refreshable tactile display. The QZSS allows users to acquire more precise position information than only with GPS around Japan. The study showed that a certain possibility to acquire an arbitrary position data of the player in the field and display it to the tactile display.
\end{abstract}

Keywords: Blind football · Visually impaired spectator Quasi-Zenith Satellites System

\section{Introduction}

In these days, blind football is more and more popular in the field of para sports. Worldwide championship games have been held regularly by the International Blind Sports Federation (IBSA) [1] and these games are reported in web media and TV programs even in Japan. As a natural consequence, the number of the spectators who would like to enjoy the game on-site is also increasing. Here, it is said that spectators at such a para sport game can be categorized into three groups [2]: the first group consists of athletes who are participating in the game, the second one includes related individuals like family members or friends of these athletes, and the third group members are unrelated individuals with disabilities. Therefore, in the case of blind football, quite a few spectators can be visually impaired people. Our department has a blind football club because we accept only students who have visual impairment, and we can see our students as spectators at the field where our team has a match. However, such visually impaired spectators have some difficulties to understand the precise situation during the game although they want to know about it. To give its information, live coverage of play-by-play announcement is the best solution though, it cannot be performed at the field because everybody there except support members do not make a noise to avoid disturbing blind players. To solve this problem, Panasonic developed a support system to provide live 
announcements and videos to the smartphone or tablet of visually impaired spectators via network [3]. This solution is enjoyable and effective, but the most problematic point is that it needs to prepare a professional sports commentator and it is difficult to realize this in local game matches.

Because of this background, we started a project to develop a support system for visually impaired spectators, which can automatically explain the situation of blind football in real time, even in local game matches.

\section{System Requirements}

To develop the blind football play-by-play system for the visually impairment spectators mentioned above, we considered the concept of the system and thought about an input method and an output method (see Fig. 1). The input method should correctly detect the position of players and the output method should effectively display the information to the spectator(s). As an output method, a synthesized voice and/or a refreshable tactile display have a possibility to be effective. From the viewpoint of realizing an automatic live coverage, voice explanation is the final goal though, tactile display is easy to utilize in these days. We can use a consumer version device by KGS Corp., which is spread in Japan and it is already shown that the blind can understand many graphical information using it [4].

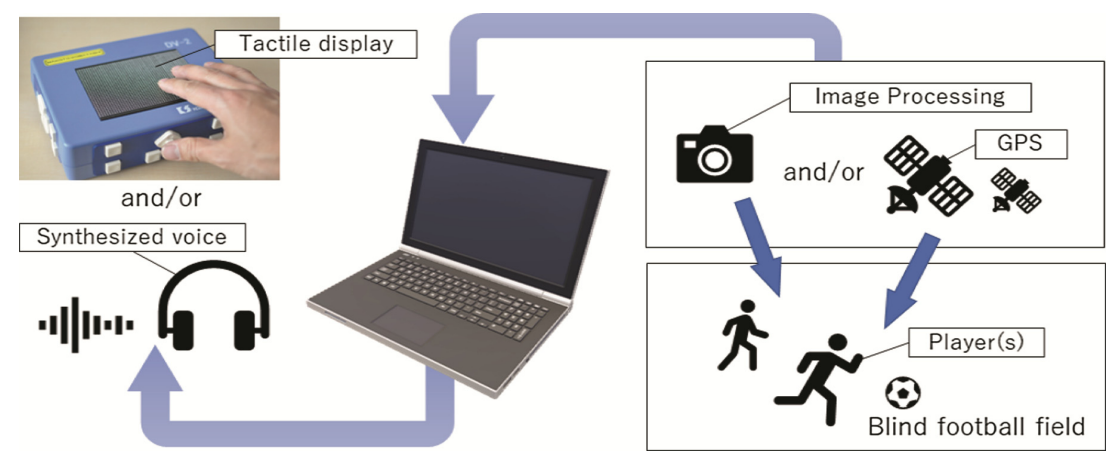

Fig. 1. Concept of blind football play-by-play system.

As an input method, we tried to consider the possibility of using a camera and GPS system to detect the position of the players. If we use cameras with image processing system, these players do not need to wear special devices. However, the position of the camera should be high enough to capture the entire field at once and setting a tall pole to carry the camera might be dangerous and difficult to establish in local game. On the contrary, GPS system forces players to wear some hardware but to prepare the total system will be easier than the camera system.

Of course, the combination of the camera system and the GPS system should be perfect though, we decided to start a basic study to find the possibility to use a GPS system as a first step, since we can use the Quasi-Zenith Satellites System (QZSS) around 
Japan with low cost. The QZSS is a national project to make GPS information more precise. It is composed of four satellites and their trajectories are always and almost on the top of the field around Japan. The fourth satellite launched in October 2017 and fullservice will start from fiscal year 2018 [5].

\section{Experimental System and Result}

After consideration of input/output method and devices, we made a set of an experimental system shown in Fig. 2 to conduct basic study. The system composed of a refreshable tactile display, a computer, a mobile wireless LAN access point, and a pair of GPS units. One of the GPS units has an ESP8266 board that can communicate to the wireless LAN access point. Another GPS unit consists of an Arduino Nano board and it directly connects to the computer. A software on the computer communicates to the GPS unit with ESP8266 via the wireless LAN, and the GPS unit sends the computer the precise time, the latitude data, and the longitude data all together. These data will be compared with the coordinate data on the same timing from another GPS unit that is connected to the computer. The compared coordinate data is expected to be more correct than stand-alone data. The calculated position of the moving GPS unit will be displayed on the refreshable tactile display.

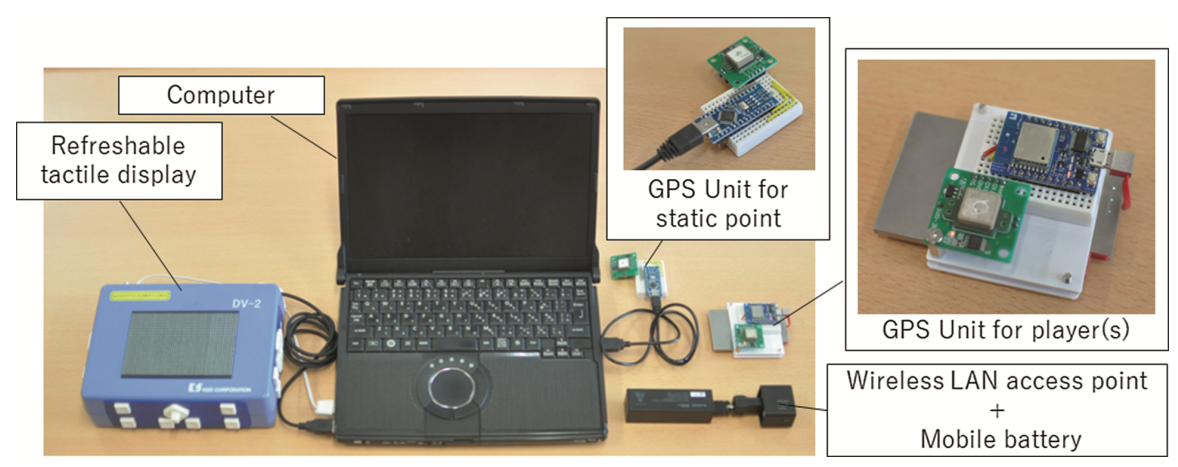

Fig. 2. Overview of an experimental system.

Figure 3 shows an example of acquired trajectory data on the soccer field in our university. A person held the GPS unit and walked around the field. This example showed a walking case which started from the corner of the field to the South direction and went back to the North direction. In this figure, the horizontal axis means latitude difference and the vertical axis means longitude difference. The left plot shows data by comparing with static point in the same timing, which is mentioned above. The right one shows simple subtracted data of acquired position and an initial position. Other trajectories had same tendency and we can say that the resolution of comparing with the static point is more precise than the subtraction data. Although sometimes it has errors, it is enough to display on the tactile display because the resolution of the display is only 48 dots by 32 dots. 

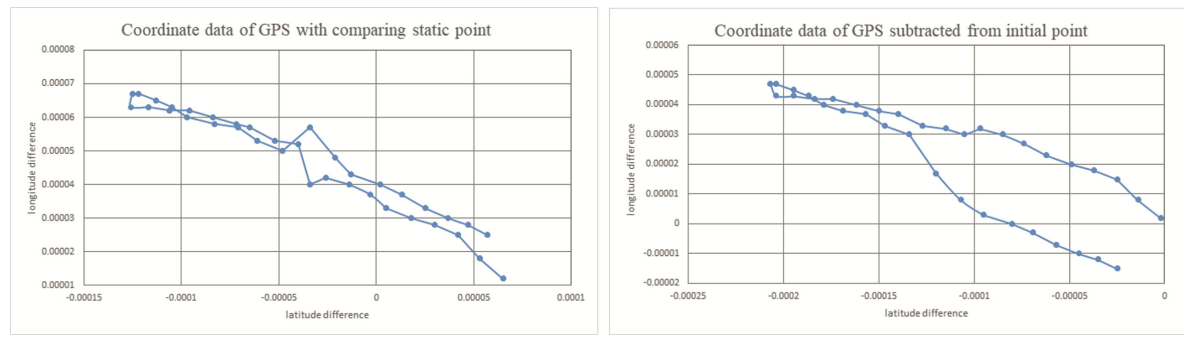

Fig. 3. Example of trajectory data

\section{Summary}

To develop a blind football play-by-play system for visually impaired spectators, a basic study of combination with QZSS and a tactile display was conducted. The results gave us a certain possibility to display an arbitrary position of the player on the tactile display. In the future, we plan to add image processing to the input method and synthesized voice to the output method.

\section{References}

1. Football - general information (IBSA web site). http://www.ibsasport.org/sports/football. Accessed 19 Mar 2018

2. Donna, D.H.: Blind football: spectators' experience of the forgotten. In: Proceeding of 19th Conference of the European Association for Sport Management, pp. 185-186 (2011)

3. Panasonic Demonstrated Spectator Solutions with VOGO Sport for Disabled Sports at JapanBrazil Blind Football Match. Panasonic newsroom, 4 April 2017. http://news.panasonic.com/ global/topics/2017/46362.html. Accessed 19 Mar 2018

4. Kobayashi, M., Watanabe, T.: Multimedia communication system for the blind. In: Ichalkaranje, N., Ichalkaranje, A., Jain, L. (eds.) Intelligent Paradigms for Assistive and Preventive Healthcare. Studies in Computational Intelligence, vol. 19, pp. 165-181. Springer, Heidelberg (2006). https://doi.org/10.1007/11418337_6

5. Murai, Y.: Project overview: quasi-zenith satellite system. In: Proceedings of the 27th International Technical Meeting of the Satellite Division of the Institute of Navigation, vol. 27, pp. 2974-3008 (2014) 
Open Access This chapter is licensed under the terms of the Creative Commons Attribution 4.0 International License (http://creativecommons.org/licenses/by/4.0/), which permits use, sharing, adaptation, distribution and reproduction in any medium or format, as long as you give appropriate credit to the original author(s) and the source, provide a link to the Creative Commons license and indicate if changes were made.

The images or other third party material in this chapter are included in the chapter's Creative Commons license, unless indicated otherwise in a credit line to the material. If material is not included in the chapter's Creative Commons license and your intended use is not permitted by statutory regulation or exceeds the permitted use, you will need to obtain permission directly from the copyright holder.

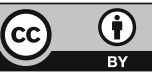

